\title{
Prevalence of disordered eating and its impact on quality of life among a group of college students in a province of west Turkey
}

\author{
Mustafa Tozun, MD, (1) Alaettin Unsal, MD, (2) Unal Ayranci, MD, (2) Gul Arslan, PhD.(2)
}

\author{
Tozun M, Unsal A,Ayranci U,Arslan G. \\ Prevalence of disordered eating and its impact \\ on quality of life among a group of college students \\ in a province of west Turkey. \\ Salud Publica Mex 2010;52:190-198.
}

\begin{abstract}
Objective.To determine the prevalence of disordered eating (DE) among a group of college students and assess its impact on quality of life. Material and Methods. This study was conducted between December $15^{\text {th }}, 2008$ and January $15^{\text {th }}$, 2009 at a Turkish University. Eating Attitudes Test-40 (EAT40) was used to identify DE. Health Related Quality of Life (HRQoL) was assessed by Medical Outcomes Study Short Form-36. Results. The prevalence of DE was 6.8\%. Presence of any physical defect (OR: 2.657), parents living separately (OR: 3. I |4), mothers having an education level of secondary school and over (OR: 2.583), and families not having social health insurance (OR: 2.603) were important risk factors $(p<0.05)$. Conclusions. The HRQoL of those with DE was worse than those without it. Periodic screenings should be done to determine DE cases.
\end{abstract}

Key words: disordered eating; quality of life; students; Turkey
Tozun M, Unsal A, Ayranci U,Arslan G.

Prevalencia de conductas alimentarias de riesgo y su impacto en la calidad de vida de un grupo de estudiantes universitarios en una provincia del oeste de Turquía. Salud Publica Mex 2010;52:190-198.

\section{Resumen}

Objetivo. Determinar la prevalencia de conductas alimentarias de riesgo (CAR) entre un grupo de estudiantes universitarios, y evaluar su impacto en la calidad de vida. Material y métodos. Este estudio se realizó entre el I5 de diciembre de 2008 y enero de 2009 en una universidad turca. Se utilizó el Eating Attitudes Test-40 (EAT-40) para identificar CAR. La calidad de vida se evaluó por el estudio de resultados médicos Short Form-36. Resultados. La prevalencia de CAR fue de $6,8 \%$. La presencia de: cualquier defecto físico (RM: $2,657)$, padres separados (RM: $3,|| 4)$, madre con nivel de educación de escuela de secundaria o más ( $R M: 2,583)$, familia sin seguro social $(R M: 2,603)$ fueron importantes factores de riesgo $(p<0,05)$. Conclusiones. La salud y calidad de vida de las personas con CAR fue peor. Se deben hacer exámenes periódicos para determinar casos de CAR.

Palabras clave: trastornos de la alimentación; calidad de vida; estudiantes; Turquía
$\mathrm{D}$ isordered eating (DE) patterns are a series of behavioral disorders which are associated with physiological and physical alterations. The etiology of $\mathrm{DE}$ is unknown, but there are many social, biological and psychological factors that play a relevant role in their pathogenesis. ${ }^{1}$ They are also known to be chronic, persistent, and refractory to treatment. ${ }^{2} \mathrm{DE}$ is a major public health problem among adolescents because of their high prevalence and their potentially serious physical and psychological consequences. ${ }^{3}$ In recent

(I) Odunpazari Community Health Center.Yenikent-Eskisehir,Turquía.

(2) Osmangazi University. Meselik Eskisehir,Turquía. 
years, psychometric tests have been used with patients with DE to evaluate different factors that may be present in these patients. Among the many existing tests, two are the most commonly used to evaluate DE: the Eating Disorders Inventory and the Eating Attitudes Test (EAT-40).

Adolescence is a transition from childhood to adulthood typically characterized by increased demands for coping with multiple social, biological, and psychological changes, as well as by the emergence of the cognitive precursors of adulthood. In some instances, the changes and demands of adolescence may leave a teenager feeling helpless, confused, and pessimistic about the future. Especially during this period, increased concerns about body image can prepare the ground for $\mathrm{DE}{ }^{4}$

Individuals with $\mathrm{DE}$ have eating-related obsessions, such as anorexia and bulimia nervosa. The personality profiles that emerged for anorexia nervosa are characterized by low novelty seeking, high harm avoidance, high persistence, and low self-directedness, and for bulimia nervosa they are high novelty seeking, high harm avoidance, and low self-directedness. ${ }^{5}$ The etiology of $\mathrm{DE}$ is widely accepted to be a combination of genetic, psychological and socio-cultural factors, i.e. they are bio-psycho-social disorders. ${ }^{6}$ Common risk factors across DE types include sex, race or ethnicity, childhood eating and gastrointestinal problems, elevated shape and weight concerns, negative self-evaluation, sexual abuse and other adverse events, and general psychiatric co-morbidity. ${ }^{7}$

In some studies previously conducted, the prevalence of $\mathrm{DE}$ among university students has been reported to vary between $3.5 \%$ and $28.5 \% .{ }^{8,9}$ Several literature research results indicate that the frequency or development of DE may be affected by certain individual characteristics -such as gender, obesity, physical defects, chronic diseases, undesirable events, smoking, alcohol consumption, body shape, and acne- and certain parental characteristics -such as father's or mother's educational level, job and family life and life event such as the death of parents..$^{10-12}$

In addition, $\mathrm{DE}$ has an impairing effect on $\mathrm{HRQOL}$, and impaired HRQoL denotes functional limitations and perceived difficulties in everyday life caused by a disease or illness. ${ }^{13}$ There are many studies reporting that HRQoL among those with DE was affected negatively. ${ }^{14,15}$

The present study was conducted to determine the prevalence of $\mathrm{DE}$ in a group of university students, to ascertain the possible risk factors related to $\mathrm{DE}$, and to assess its impact on HRQoL.

\section{Materials and Methods}

\section{Setting}

The present study was conducted in a cosmopolitan city with two universities. The study was carried out at Anatolia University, which has 21 schools and colleges with roughly 25000 students; it was conducted at the university's College of Physical Education.

\section{Instruments}

A demographic questionnaire was prepared by the researchers that included information about the students' sociodemographic, individual and familial characteristics, as well as their health status.

The Eating Attitudes Test-40 (EAT-40) was used to identify DE. This test, developed by Garner and Garfinkel, uses a self-assessment scale that objectively measures the symptoms of DE. ${ }^{16}$ Its validity and reliability was conducted by a study in Turkey by Savasir and Erol. ${ }^{17}$ The scale consists of 40 questions, the answers to which were evaluated with a six-point Likert scale, from "always" to "never." The resulting scores ranged between 0 and 120 points and individuals scoring 30 points and over were considered as persons with a high risk of DE.

HRQoL was assessed by the Medical Outcomes Study Short Form-36 (SF-36), which is the health survey questionnaire most widely used for rating HRQoL. The original questionnaire was developed by Ware and Sherbourne ${ }^{18}$ and reliability and validity studies for the Turkish version of SF-36 were performed by Kocyigit et al. ${ }^{19}$ This is a self-evaluation instrument consisting of 36 items. The individuals answered the questions in the SF-36 scale according to their status over the previous four weeks. The scores ranged between 0 and 100 for each separate area. As the scores obtained from the scale increased, HRQoL also positively increased.

\section{Sampling}

This study was conducted between December 15th, 2008 and January 15th, 2009. The number of the students studying in the college was 745 , most of whom $(n=542)$ were females. Of the 745 students, 66 were excluded from the survey due to unwillingness to participate in the research $(n=17)$ and not being in classes at the time of the study $(\mathrm{n}=49)$. The remaining $679(679 / 745)$ students constituted the study group. 


\section{Procedures}

All subjects were told that participation in the investigation was strictly voluntary and that the data collected would not be used for anything except for this research study. Following the completion of the questionnaires and inventories, their body mass index (BMI) was calculated by measuring the heights and weights of each student. Those who had BMIs of $25 \mathrm{~kg} / \mathrm{m}^{2}$ and over were defined as overweight or obese. ${ }^{20}$ Students were also examined for the existence of acne vulgaris through physical inspection.

Smoker was defined as having smoked at least one cigarette per day, and alcohol drinker as having reported a weekly alcohol intake greater than $30 \mathrm{ml}$ of ethanol. The amount of pocket money that the students obtained from their family was evaluated as enough or insufficient according to the students' own opinions. Those having physical or sensorial problems were identified if any visual impairment, hearing and orthopedic problems, etc. were present. Acne vulgaris was determined with visual examination.

\section{Legal ethical consent}

Ethical permission for the study was obtained prior to collecting data by contacting and receiving approval from the appropriate authority at the Anatolia University. Informed consent was obtained from the subjects participating in the study according to that established by the Ethical Principles for Medical Research Involving Human Subjects in the Helsinki Declaration.

\section{Statistics}

The statistical analysis was carried out using the Student's t-test for continuous variables and the chi-square test for categorical variables. Significantly related variables were assessed using a model with a backward stepwise logistic regression analysis.

\section{Results}

\section{Sociodemographic data}

Of the participants, $492(72.5 \%)$ were male and 187 $(27.5 \%)$ female. The average age of the participants was $21.6 \pm 2.2$ years (range $=17-29$ years). Nearly $30 \%$ of students were in the $4^{\text {th }}$ year $(31.7 \%)$, followed by the $1^{\text {st }}$ year $(22.5 \%)$. Most students $(36.2 \%)$ were in the age group of 20 and below. Seven students (1.0\%) reported that they had no siblings, and $113(16.6 \%)$ reported that they had 5 siblings or over. Nearly $50 \%$ of the students
(48.2\%) reported that they lived with their friends. The present study showed a prevalence of DE of $6.8 \%(n=46)$. Of the students with DE, 29 (63.0\%) were male and 17 $(37.04 \%)$ female. Detailed sociodemographic characteristics of students by status of disordered eating are presented in Table I.

\section{EAT-40 scores}

The average score that the students obtained from the EAT-40 was $15.13 \pm 7.41$, ranging from 1 to 40 , with scores of $16.81 \pm 7.79$ and $14.49 \pm 7.16$ for females and males, respectively $(t=3.670, \mathrm{df}=677, p<0.001)$ (data not shown).

\section{Individual characteristics}

The prevalence of overweight/obesity in the study group was $8.7 \%(n=59)$. There was no difference between those with DE and without DE in terms of the frequency of $\mathrm{DE}(p>0.05)$. The number of those with any kind of physical or sensorial problem was $59(8.7 \%)$, and a significant difference in frequency of DE was found between those who had physical or sensorial problems and those who did ( $15.3 \%$ vs $6.0 \%$, respectively; $p<0.05)$. The number of those with any type of chronic disease requiring the use of drugs was 43 (6.3\%). It was found that the frequency of smoking among the students was $26.7 \%$ $(\mathrm{n}=181)$ and that frequency of alcohol consumption was $28.4 \%$ ( $\mathrm{n}=193$ ). The number of students experiencing an unwanted event in the past was $184(27.1 \%)$ and the prevalence of facial acne vulgaris was $29.3 \%(\mathrm{n}=199)$. The students' DE status according to their individual characteristics is presented in Table II.

\section{Parental characteristics}

There was no difference between those whose mother or father were dead and those whose mother or father were alive in terms of the prevalence of $\mathrm{DE}(p>0.05)$. The number of those whose father or mother were living separately was $43(6.3 \%)$. The number of those whose mother's educational level was secondary school and over was $256(37.7 \%)$, and $431(63.5 \%)$ students had fathers with an educational level of secondary school and over. The frequency of DE was higher for those whose father or mother were living separately, those whose mother's educational level was secondary school and over, and those whose father's educational level was secondary school and over ( $p<0.05$ each). The students' DE status according to their parental characteristics is detailed in Table III. For the females, the frequency of DE was higher for those whose father and mother were liv- 
Table I

SOCIODEMOGRAPHIC CHARACTERISTICS OF STUDENTS BY STATUS OF DISORDERED EATING. ANATOLIA UNIVERSITY, eSKISEHIR, TURKey, DeCEMBER 2008 to JANUARY 2009

\begin{tabular}{|c|c|c|c|c|}
\hline \multirow[b]{2}{*}{ Sociodemographics } & \multicolumn{3}{|c|}{ Disordered eating } & \\
\hline & $\begin{array}{c}\text { Yes } \\
n(\%) *\end{array}$ & $\begin{array}{c}\text { No } \\
n(\%) *\end{array}$ & $\begin{array}{c}\text { Total } \\
n(\%) * *\end{array}$ & $\chi^{2} ; p$ value \\
\hline
\end{tabular}

Sex

\begin{tabular}{lllll} 
Male & $29(5.9)$ & $463(94.1)$ & $492(72.5)$ & \\
\cline { 1 - 3 } Female & $17(9.1)$ & $170(90.9)$ & $187(27.5)$ & $2.192 ; 0.139$
\end{tabular}

Age group

\begin{tabular}{lrrr}
19 and under & $10(8.8)$ & $104(91.2)$ & $114(16.8)$ \\
\hline $20-21$ & $17(6.6)$ & $239(93.4)$ & $256(37.7)$ \\
\hline $22-23$ & $5(3.0)$ & $163(97.0)$ & $168(24.7)$ \\
\hline 24 and over & $14(9.9)$ & $127(90.1)$ & $141(20.8)$
\end{tabular}

$6.787 ; 0.079$

\begin{tabular}{crrr}
$\begin{array}{c}\text { College year } \\
1\end{array}$ & $12(7.1)$ & $157(92.9)$ & $169(24.9)$ \\
\hline 2 & $12(8.5)$ & $130(91.5)$ & $142(20.9)$ \\
\hline 3 & $6(3.9)$ & $147(96.1)$ & $153(22.5)$ \\
\hline 4 & $16(7.4)$ & $199(92.6)$ & $215(31.7)$
\end{tabular}

$2.784 ; 0.426$

Number of siblings

\begin{tabular}{lccc} 
None & $0(0.00)$ & $7(100.0)$ & $7(1.0)$ \\
\hline I or 2 & $25(7.3)$ & $319(92.7)$ & $344(50.7)$ \\
\hline 3 or 4 & $13(6.0)$ & $202(94.0)$ & $215(31.7)$ \\
\hline 5 and over & $8(7.1)$ & $105(92.9)$ & $113(16.6)$
\end{tabular}

$0.838 ; 0.840$

Birth order in family

\begin{tabular}{lccc} 
First & $19(7.7)$ & $229(92.3)$ & $248(36.5)$ \\
\hline Second & $18(8.0)$ & $208(92.0)$ & $226(33.3)$ \\
\hline Third & $3(2.6)$ & $114(97.4)$ & $117(17.2)$ \\
\hline Fourth and over & $6(6.8)$ & $82(93.2)$ & $88(13.0)$
\end{tabular}

$4.100 ; 0.251$

Living place

\begin{tabular}{lrrr} 
With family & $13(8.7)$ & $136(91.3)$ & $149(21.9)$ \\
\hline Dormitory & $13(7.4)$ & $163(92.6)$ & $176(25.9)$ \\
\hline Alone at home & $4(14.8)$ & $23(85.2)$ & $27(4.0)$ \\
\hline At home with friends & $16(4.9)$ & $311(95.1)$ & $327(48.2)$
\end{tabular}

Receiving pocket money from family

\begin{tabular}{llrr} 
Adequate & $21(6.4)$ & $308(93.6)$ & $329(48.5)$ \\
\hline Inadequate & $25(7.1)$ & $325(92.9)$ & $350(51.5)$ \\
\hline Total & $46(6.8)$ & $633(93.2)$ & $679(100.0)$
\end{tabular}

ing separately $(26.7 \%$ vs $7.6 \%, p<0.05)$, whose mother's educational level was secondary school and over $(14.1 \%$ vs $5.5 \%, p<0.05)$, whose father's educational level was secondary school and over $(12.2 \%$ vs $3.1 \%, p<0.05)$, whose father was unemployed $(12.3 \%$ vs $3.1 \%, p<0.05)$ and for those whose family had no social health insurance $(25.0 \%$ vs $7.6 \%, p<0.05)$. However, for the males, the frequency of DE was higher only for those whose mother's educational level was secondary school and over $(9.0 \%$ vs $4.1 \%, p<0.05)$ (data not published). 
Table II

INDIVIDUAL CHARACTERISTICS OF STUDENTS BY STATUS OF DISORDERED EATING.

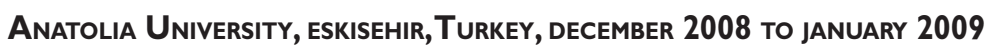

\begin{tabular}{ccccc} 
& \multicolumn{3}{c}{ Disordered eating } & Statistical analysis \\
\cline { 2 - 3 } Individual characteristics & Yes & No & Total & $\chi^{2} ; p$ value
\end{tabular}

Overweight/obese

\begin{tabular}{rrrrr} 
Yes & $4(6.8)$ & $55(93.2)$ & $59(8.7)$ & \\
\cline { 1 - 3 } No & $42(6.8)$ & $578(93.2)$ & $620(91.3)$ & Fisher exact test; $0.58 I^{*}$
\end{tabular}

Physical or sensorial problems

\begin{tabular}{lrrr} 
Yes & $9(15.3)$ & $50(84.7)$ & $59(8.7)$ \\
\hline No & $37(6.0)$ & $583(94.0)$ & $620(91.3)$
\end{tabular}

$7.356 ; 0.007$

Any chronic disease needing the use of any medicine

\begin{tabular}{cccc} 
Yes & $5(11.6)$ & $38(88.4)$ & $43(6.3)$ \\
\hline No & $41(6.4)$ & $595(93.6)$ & $636(93.7)$ \\
$\begin{array}{c}\text { Smoking } \\
\text { Yes }\end{array}$ & $10(5.5)$ & $171(94.5)$ & $181(26.7)$ \\
\hline No & $36(7.2)$ & $462(92.8)$ & $498(73.3)$
\end{tabular}

$0.610 ; 0.435$

\begin{tabular}{l}
$\begin{array}{l}\text { Alcohol consumption } \\
\text { Yes }\end{array}$ \\
\hline No \\
\hline
\end{tabular}

$0.425 ; 0.515$

Any event being experienced previously

\begin{tabular}{llll} 
Yes & $10(5.4)$ & $174(94.6)$ & $184(27.1)$ \\
\hline No & $36(7.3)$ & $459(92.7)$ & $495(72.9)$
\end{tabular}

$0.717 ; 0.397$

Facial acne vulgaris

\begin{tabular}{lllr} 
Yes & $15(7.5)$ & $184(92.5)$ & $199(29.3)$ \\
\hline No & $31(6.5)$ & $449(93.5)$ & $480(70.7)$ \\
\hline Total & $46(6.8)$ & $633(93.2)$ & $679(100.0)$
\end{tabular}

$0.259 ; 0.610$

\section{Logistic analysis results}

Table IV shows the logistic analysis results for the variables age group, physical or sensorial problems, whether the father and mother lived separately, mother's educational level, father's educational level, health insurance status of the family, and history of any physical disorders in the family that had significant relationships with DE in the bivariate analysis.

\section{Quality of life results}

The average scores received for the items on the SF-36 scale were lower for the students with DE as compared to those without DE $(p<0.05)$, with the exception of 'body pain' and 'social functioning' ( $p>0.05$ for each one). Table $\mathrm{V}$ indicates the average scores on the SF-36 scale for those with and without DE.

\section{Discussion}

DE is considered the third most prevalent chronic health condition among adolescent females. In the present study, $6.8 \%$ of college students were rated with abnormal eating attitudes by the EAT-40; this appears to be similar to findings by other studies performed in Turkey and other countries..$^{21,22}$

$\mathrm{DE}$ can be expected to be more common among those with a physical or sensorial problem, which is consistent with the present study's findings that DE was 
Table III

Parental characteristics of students by status of disordered eating. ANATOLIA UNIVERSity, ESKISEHIR, TURKEY, DECEMBER 2008 to JANUARY 2009

\begin{tabular}{ccccc} 
& \multicolumn{3}{c}{ Disordered eating } & Statistical analysis \\
\cline { 2 - 4 } Parental characteristics & Yes & No & Total & $\chi^{2} ; p$ value
\end{tabular}

Father or mother were alive

\begin{tabular}{rrrr} 
Yes & $45(7.2)$ & $580(92.8)$ & $625(92.0)$ \\
\hline No & $I(1.9)$ & $53(98.1)$ & $54(8.0)$
\end{tabular}

Fisher exact test; 0.165

Father or mother were living separately

\begin{tabular}{rrrr} 
Yes & $8(18.6)$ & $35(81.4)$ & $43(6.3)$ \\
\hline No & $38(6.0)$ & $598(94.0)$ & $636(93.7)$
\end{tabular}

$10.172 ; 0.001$

Mother's educational level

\begin{tabular}{lrrr} 
Primary school or below & $19(4.5)$ & $404(95.5)$ & $423(62.3)$ \\
\hline Secondary school or over & $27(10.5)$ & $229(89.5)$ & $256(37.7)$
\end{tabular}

Father's educational level

\begin{tabular}{llll} 
Primary school or below & $10(4.0)$ & $238(96.0)$ & $248(36.5)$ \\
\hline Secondary school or over & $36(8.4)$ & $395(91.6)$ & $431(63.5)$
\end{tabular}

$4.653 ; 0.031$

Mother's job

\begin{tabular}{lrrr} 
Yes & $5(8.9)$ & $51(91.1)$ & $56(8.2)$ \\
\hline No (unemployed/housewife/retired) & $41(6.6)$ & $582(93.4)$ & $623(91.8)$
\end{tabular}

Father's job

\begin{tabular}{llll} 
Yes & $30(7.8)$ & $355(92.2)$ & $385(56.7)$ \\
\hline No (unemployed/retired) & $16(5.4)$ & $278(94.6)$ & $294(43.3)$
\end{tabular}

I.458; 0.227

Family's income level

\begin{tabular}{lrrr} 
Poor & $7(7.8)$ & $83(92.2)$ & $90(13.2)$ \\
\hline Average & $27(6.3)$ & $402(93.7)$ & $429(63.2)$ \\
\hline Good & $12(7.5)$ & $148(92.5)$ & $160(23.6)$
\end{tabular}

$0.434 ; 0.805$

Health insurance status of family

\begin{tabular}{lrrr} 
Insured & $39(6.2)$ & $586(93.8)$ & $625(92.0)$ \\
\hline Uninsured & $7(13.0)$ & $47(87.0)$ & $54(8.0)$
\end{tabular}

History of any chronic disease in family

\begin{tabular}{rrrr} 
Yes & $4(16.0)$ & $21(84.0)$ & $25(3.7)$ \\
\hline No & $42(6.4)$ & $612(93.6)$ & $654(96.3)$
\end{tabular}

Fisher exact test; 0.082

History of obesity in family

\begin{tabular}{lrrr} 
Yes & $7(10.4)$ & $60(89.6)$ & $67(9.9)$ \\
\hline No & $39(6.4)$ & $573(93.6)$ & $612(90.1)$ \\
\hline Total & $46(6.8)$ & $633(93.2)$ & $679(100.0)$
\end{tabular}


Table IV

SIGNIFICANT INDEPENDENT VARIABLES FOR DISORDERED EATING ACCORDING TO LOGISTIC REGRESSION ANALYSIS (THE THIRD STEP).ANATOLIA UNIVERSITY, ESKISEHIR, TURKEY, DECEMBER 2008 to JANUARY 2009

\begin{tabular}{|c|c|c|c|c|c|}
\hline Variables & B & SE & $p$ & OR & $95 \% \mathrm{Cl}$ \\
\hline Constant & -3.422 & 0.271 & 0.000 & & \\
\hline \multicolumn{6}{|c|}{ Physical or sensorial problem (reference: No) } \\
\hline Yes & 0.977 & 0.412 & 0.018 & 2.657 & $0.887-4.209$ \\
\hline \multicolumn{6}{|c|}{ Mother or father were living separately (reference: No) } \\
\hline Yes & 1.136 & 0.440 & 0.010 & 3.114 & $1.315-7.373$ \\
\hline \multicolumn{6}{|c|}{ Mother's educational level (reference: primary school and lower) } \\
\hline Secondary school and over & 0.949 & 0.318 & 0.003 & 2.583 & $1.384-4.820$ \\
\hline \multicolumn{6}{|c|}{ Family's social health insurance (reference:Yes) } \\
\hline No & 0.957 & 0.455 & 0.036 & 2.603 & $|.067-6.35|$ \\
\hline
\end{tabular}

Table V

MEAN SCORES OF SF-36 ITEMS FOR THOSE WITH AND WITHOUT DISORDERED EATING. ANATOLIA UNIVERSITY, ESKISEHIR, TURKEY, DECEMBER 2008 to JANUARY 2009

\begin{tabular}{|c|c|c|c|}
\hline & & & \\
\hline & & & statistical analysis \\
\hline Items & $\begin{array}{l}\text { Yes }(n=46) \\
\text { (mean } \pm S d)\end{array}$ & $\begin{array}{r}\text { No }(n=633) \\
\text { (mean } \pm S d)\end{array}$ & t-test; $p$-value \\
\hline
\end{tabular}

\begin{tabular}{llll} 
Physical functioning & $69.69 \pm 28.52$ & $88.57 \pm 16.54$ & $7.026 ; 0.000$ \\
\hline Role-physical & $66.85 \pm 36.15$ & $80.25 \pm 30.73$ & $2.821 ; 0.005$ \\
\hline Body pain & $67.72 \pm 22.87$ & $70.06 \pm 21.59$ & $0.703 ; 0.482$ \\
\hline General health perception & $54.78 \pm 20.24$ & $63.36 \pm 18.38$ & $3.033 ; 0.003$ \\
\hline Vitality & $52.50 \pm 18.91$ & $58.05 \pm 16.55$ & $2.174 ; 0.030$ \\
\hline Social functioning & $72.01 \pm 20.78$ & $70.62 \pm 22.20$ & $0.413 ; 0.680$ \\
\hline Role-emotional & $49.28 \pm 40.21$ & $62.19 \pm 40.12$ & $2.108 ; 0.035$ \\
\hline Mental health & $45.92 \pm 16.45$ & $55.24 \pm 18.42$ & $3.335 ; 0.001$ \\
\hline
\end{tabular}

more frequent among those with physical or sensorial problems (OR:2.657, $p<0.05)$. In addition, Pruneti et al. have reported that there was a relationship between body perception and DE, especially for females. ${ }^{22}$

As part of the developmental process of adolescence, the individual undergoes dramatic physical, psychological, and social changes. For the adolescent with a chronic illness, these changes may impact the ability of the adolescent and their family to successfully negotiate the demands of this period. ${ }^{6}$ Chronic health conditions may increase dissatisfaction with the body and feelings of isolation from peers, potentially increasing the risk of psychopathology associated with adolescence, such as eating and body image distortion. ${ }^{23}$ The present study did not find any differences in frequency of DE $(p>0.05)$ between the students who had any chronic disease di- 
agnosed by a physician and those who did not; this is consistent with the study by Ilhan et al. ${ }^{24}$ However, there are also many studies reporting that DE is seen more frequently in adolescents who have chronic diseases. ${ }^{25}$

In the present study, there was no connection between those with facial acne vulgaris and those without in terms of the frequency of $\mathrm{DE}(p>0.05)$. This could be explained by the fact that the number of students in the study group was low and that the frequency of acne was rare. However, for those with DE, it is known that the facial acne was significantly more frequent. By way of an explanation for this, it has been suggested that acne negatively affects psychosocial health due to the psychological issues attached to it, which include pain and discomfort, shame, body image concerns, social assertiveness, obsessive-compulsiveness, embarrassment, and social inhibition. ${ }^{10}$

It has been known that stressful life events -such as parents living separately, the loss of one or both parents, and divorce- are significant risk factors for DE. ${ }^{26}$ This study did not find any difference between the students whose parents were alive and those whose parents were dead in terms of the frequency of DE $(p>0.05)$. However, for students whose parents were divorced/separated, the frequency of DE was found to be higher when compared to those whose parents were living together $(p<0.05)$. Logistic regression analysis conducted for the present study also determined that having parents who live apart or who are divorced is an important risk factor for DE (OR: 3.114; $p<0.05)$. Robinson and Andersen also reported similar results. ${ }^{27}$

Kim and Yang indicated that there was a negative relationship between parent-adolescent communication and DE. ${ }^{11}$ One of the important factors affecting communication between parents and children is the education level of parents. It is expected that parents with higher education levels have better relationships with their children. In the present survey, however, the frequency of DE was significantly higher for students whose mother and father's education levels were secondary school and over than for those whose mother and father's education level was primary school and below $(p<0.05)$. Likewise, the logistic regression analysis showed that having mothers with an education level of secondary school and over was an important risk factor for DE $(O R: 2.583 ; p<0.05)$. Contrary to this, Díaz Benavente et al. reported that they did not find any relationship between education level and EAT- 40 scores, ${ }^{28}$ which suggests that further studies are warranted.

The present study determined that families with no social health insurance were at greater risk of $\mathrm{DE}$ $(O R: 2.603 ; p<0.05)$, which is consistent with the studies by some researchers indicating that there was a connec- tion between socioeconomic status and the frequency of DE. ${ }^{12,29}$

The present study found that HRQoL was worse for students with $\mathrm{DE}$. The average scores for all the items on the SF-36 scale, except for 'body pain' and 'social functioning' ( $p>0.05$, for each one), were lower for students with DE than for those without ( $p<0.05$, for each one). Similarly, many studies indicated that the average scores for all the items on the SF-36 scale were lower for those with DE when compared to those without DE. ${ }^{15,16}$

Several important limitations should be considered when interpreting the results of the present study, one which is that this study was cross-sectional, thus precluding inferences of causality among variables. The second limitation is the use of self-reporting. Third, the sample for the current study comprised a group of students in just one city in Turkey, which may limit the generalization of results. Thus, a study with a large sample containing different universities in the country needs to be conducted. Finally, since the scale was used as a screening test rather than a definite diagnosis, those who were at the risk of eating disorders were not actually diagnosed with EAT-40.

\section{Conclusions}

The present study found that DE among university students was a significant public health problem and that the HRQoL of those with DE was worse. As a result, we conclude that effective psychological counseling services for university students should be provided and that periodic screenings should be done to determine DE cases in the early stages. Finally, DE cases should be referred to specialized psychiatry centers for specific diagnosis and treatment, which could result in an improvement in HRQoL levels.

\section{Acknowledgements}

We would like to thank the students for their valuable efforts and university management for their permission. There is no conflict of interest for this study.

\section{References}

I. RTI-UNIC Evidence-Based Practice Center. Management of Eating Disorders. North Carolina: Research Triangle Park. AHRQ Publication No. 06-E010, 2006.

2. Fairburn CG, Harrison PJ. Eating disorders. Lancet 2003;361:1913-4. 3. Lau RR, Qudarel MJ, Hartman KA. Development and change of young adults' preventive health beliefs and behavior: influence from parents and pers. J Health Soc Behav 1990;31:240-59. 
4. Patterson JM, McCubbin HI.Adolescent coping style and behaviors: conceptualization and measurement. J Adolesc 1987; 10:163-86. 5. Fassino S,Abbate-Daga G,Amianto F, Leombruni P, Boggio S, Rovera GG.Temperament and character profile of eating disorders: a controlled study with the Temperament and Character Inventory. Int J Eat Disord 2002;32:412-25.

6. Gonzalez A, Kohn MR, Clarke SD. Eating disorders in adolescents. Aust Fam Physician 2007;36:614-9.

7. Berkman ND, Bulik CM, Brownley KA, Lohr KN, Sedway JA, Rooks A, et al. Management of eating disorders. Evid Rep Technol Assess (Full Rep) 2006; $135: 1-166$

8. le Grange D, Louw J, Russell B, Nel T, Silkstone C. Eating attitude and behaviours in South african adolescents and young adults. Transcult Psychiatry 2006;43:40I-7.

9. Celikel FC, Cumurcu BE, Koc M, Etikan I,Yucel B. Psychologic correlates of eating attitudes in Turkish female college students. Compr Psychiatry 2008;49:188-94

10. Tan JK. Psychosocial impact of acne vulgaris: evaluating the evidence. Skin Therapy Lett 2004;9:9.

I I. Kim KH,Yang KM. The relationship between eating disorders and parent-adolescent communication in middle school students in rural areas. Taehan Kanho Hakhoe Chi 2008;38:55-63.

12. Chen $\mathrm{H}$, Jackson T. Prevalence and sociodemographic correlates of eating disorder endorsements among adolescents and young adults from China. Eur Eat Disord Rev 2008;16:375-85.

13.The WHOQOL Group. The World Health Organization Quality of Life Assessment (WHOQOL): Position Papaer From the World Health Organization. Soc Sci Med 1995; 10:1403-9.

I4. Mond JM, Hay PJ, Rodgers B, Owen C, Beumont PJ.Assessing quality of life in eating disorder patients. Qual Life Res 2005; I4:I7|-8.

15. de le Rie SM, Noordenbos G, van Furth EF. Quality of life and eating disorders. Qual Life Res 2005; I 4: I5 I I-22.

16. Garner DM, Garfinkel PE.The Eating Attitudes Test:An index of the symptoms of anorexia nervosa. Psychol Med 1979;9:273-9.

17. Savasir I, Erol N.Yeme Tutumu Testi:Anoreksiya Nevroza Belirtileri Indeksi. Psikoloji Dergisi 1989;7:19-25

18. Ware JE, Sherbourne CD. The MOS 36-item short-form health survey (SF-36). I. Conceptual framework and item selection. Med Care 1992;30:473-83.
19. Kocyigit $\mathrm{H}$,Aydemir O, Olmez N, Memis A. Reliability and validity of the Turkish version of Short-Form-36 (SF-36). Turkish J Drugs Therap 1999; 12:102-6

20.World Health Organization. Obesity: preventing and managing the global epidemic Report of a WHO consultation on obesity. Technical report series No 894. Geneva:WHO, 2000.

2I.Asci FH,Tuzun M, Koca C.An examination of eating attitudes and physical activity levels of Turkish University students with regard to selfpresentational concern. Eat Behav 2006;7:362-7.

22. Pruneti C, Fontana F, Donalizio M, Buracchi G, Bicchieri L. Eating behaviour and body image: epidemiological study on 4,243 senior and junior high school's Italian students. Minerva Pediatr 2004;56:395-4I0. 23.Thompson JK, Heinberg LJ,Altabe M, Tantleff-Dunn S. Exacting Beauty: Theory, Assessment and Treatment of Body Image Disturbance. Washington, DC:American Psychological Association, 1999.

24. Ilhan MN, Ozkan S, Aksakal N,Aslan S, Durukan E, Maral I. Bir Tip Fakultesi Ogrencilerinde Olasi Yeme Bozuklugu Sikligi. Turkiye'de Psikiyatri Dergisi 2006;8:I5I-5.

25. Smith FM, Latchford GJ, Hall RM, Dickson RA. Do chronic medical conditions increase the risk of eating disorder? A cross-sectional investigation of eating pathology in adolescent females with scoliosis and diabetes. J Adolesc Health 2008;42:58-63.

26. Conte FF. Eating Disorders and Adolescents: Conflict of Self Image. Curriculum Unit 84.05.05. New Jersey:Yale-New Haven Teachers Institute, 1984. http://yale.edu/ynhti/curriculum/units/ 1984/5/84.05.05.x.html. Accessed on 26 January 2009.

27. Robinson P,Andersen A. Anorexia nervosa in American blacks. J Psychiatr Res 1985; 19:183-8.

28. Díaz Benavente M, Rodríguez Morilla F, Martín Leal C, Hiruela Benjumea MV. Risk factors related with eating disorders in a community of adolescents. Aten Primaria 2003;32:403-7.

29. Latzer Y,Vander S, Gilat I. Socio-demographic characteristics of eating disorder patients in an outpatient clinic: a descriptive epidemiological study. Eur Eat Disord Rev 2008;16:139-46. 